\title{
Dialogue 1: ODA graduation in times of changing global relations and partnerships
}

Any political phenomenon can only be properly understood in its broader context. Questions of international cooperation are thus necessarily framed by historical processes and relations of power. We therefore start our first discussion with an examination of the global 'status quo' and embed the topic of this publication, ODA graduation, into the shifting world order, analysing current roles and settings in international relations and identifying changes in positions, status and categories. What are the overarching issues determining world politics and who are the old and the new actors driving them? What is the impact of these global shifts on international cooperation, especially development cooperation? Of what relevance are roles, status and categories and what is the impact of changes in positions and relations? What challenges face multilateralism and what ways exist to maintain and renew strategic partnerships and shared values?

The discussion was held between Imme Scholz, Deputy Director of the German Development Institute / Deutsches Institut für Entwicklungspolitik (DIE), and Elizabeth Sidiropoulos, Chief Executive of the South African Institute of International Affairs. It was facilitated by Andreas Proksch, Director General of the Department for Sector and Global Programmes at GIZ and Juliane Kolsdorf, editor of this publication. ${ }^{32}$

Let me start with a brief anecdote. After finishing university, I myself [Andreas Proksch] was at the German Development Institute for the Postgraduate Course. On the first day of the course, there was a very flamboyant head of department talking to us about possible world models, as he called it at that time. He wanted to give us an idea of the latest thinking on the future development of our world, of our political system on our planet. At that time, the world was still very clearly divided into the rich and the poor, the North and the South, and already one of his ideas about the future was that this easy and clear distinction would gradually become lost in the years and decades to come, up to a point where we would have to face the possibility of arriving at a completely chaotic system in which it is no longer possible to make a clear distinction between the roles and positions of all the different nations and countries. I still

32 For better distinction from the discussants, the inputs and questions by the facilitators are displayed in italic without naming the respective person. 
see him standing at the flipchart, thinking decades ahead, and today, nearly 40 years later, we are discussing similar issues, also with the same institute.

We all know that the status quo is changing rapidly, and we would like to use the time with you to look in a bit more detail at what the global status quo is, and what the major ongoing changes are. We would naturally like to shed some light on the issue of different countries moving towards ODA graduation: bigger, powerful players like China, Brazil, Turkey and also smaller actors, like Chile, Malaysia, small island countries, etc. We want to discover what role these two groups could play in shaping international orders, relations and partnerships. Let us start with how the shifting world order is affecting international cooperation. How would you describe the current global order at present? Elizabeth Sidiropoulos: It is in transition. It is highly unpredictable. It is reminiscent of Gramsci's analysis in the 1930s that the old is dead but the new is not yet born. ${ }^{33}$ It is also an environment where identities, distinctions and classifications are becoming much more diffuse and much less defined. If I reflect on conversations that are happening here in South Africa, some of the debates are almost a bit anachronistic in that they are occurring and reflecting a narrative that is 30,40 years old, but at the same time, the way in which countries like South Africa are engaging pragmatically takes account of the fact that this is now a very different world from the 60 s and the 70 s, as you alluded to in your introduction. It was a North-South world, a very clear polar distinction. That is now much less the case; it has become much more mixed. And certainly, in the debate that is happening in the North, there is also a very clear realisation that there are significant developmental challenges even in wealthy countries; and that is the whole debate around inequality.

Basically, everything that we have learned at university and that we have engaged with over the last few decades is now being questioned: international cooperation, which development economists and people working in the development field thought was an important contribution by the North to help the South, to help poor economies. Southern actors would say it was also a historical responsibility, the result of the legacies of colonialism, that the North has an obligation to do that.

With all the geopolitical changes happening, that more altruistic dimension of a discussion around international cooperation has also been questioned and perhaps eroded. In certain countries less, in others more, but I would argue that it is a very clear trend across the world. Some of that has been a result of the rise of new actors from the developing world, who take a very different approach to international cooperation. It is all about mutual benefit and it is about commercial opportunities, not about charity. 
Imme Scholz: I think there are several sources of these changes. One is that rising powers - not only the large regional powers and new global players you alluded to but a second grouping, middle-income countries - are moving towards graduation from ODA while retaining many characteristics of what we used to call underdevelopment, regarding state capacities, redistribution of income, social and economic infrastructure and knowledge capacities, although I would say except for China, which is really a special case. There are changes in economic shares and participation in trade and in finance, but I want to highlight the remaining disparities.

A second source of this changing world order is the weakening of the multilateral system as we used to know it, its principles, its rules, its institutions, its procedures, which has to do especially with the emergence of China and Russia and with the recent political divisions within "the West". These trends question the Westphalian system and the expectation of the "West" that economic development goes along with a development of institutions and political regimes towards democracy, participation and human rights. For me, the changes we are now witnessing in political references, nationally and globally, are frightening because our only historical reference is that in such situations, war will break out. We do not know what war will look like, but I think this is clearly on the cards.

And third, I would add the degree and plurality of environmental changes we are facing. The fires in Australia have shown that vulnerability to global environmental change is not only a feature of developing countries or of extremely poor and vulnerable countries.

So, I would see these three sources and, of course, they interact. The ways of understanding short-term crises or deep crises and dealing with them which we have used in the past do not seem to hold anymore. We had an approach in 2008 and 2009 to the global crisis of the financial system - but will it work next time? The references are unclear today.

Elizabeth Sidiropoulos: Just to take this further: about ten years ago, there was a lively academic debate about the fact that the liberal international order is constructed in such a way that it is open enough to be able to adapt and to bring in people and countries who can feel that they are part of it. ${ }^{34}$ The liberal international order, as it was constituted, particularly in the immediate post-Cold War time, was beneficial to emerging economies. Suddenly, China benefitted significantly from the system, as did many other developing economies. And certain academics wrote that the liberal order as such is open enough to be able to adapt - so that we do not have to deal with the Thucydides trap, what Graham Allison referred to in his book a few years ago, about the fact that when a rising 
power disrupts the dominant hegemon, it often ends up badly, or even in $w^{35}{ }^{35}$. But what we have really seen in the last seven or eight years is that this is not the case. It is not the case because countries like China, emerging superpowers, do believe that they need to be able to stamp their authority and their particular views on norms on the system. This has gone together with the coming to power of president $\mathrm{Xi}$; he has taken a much more assertive approach in international affairs.

So, the response from those that have all the power in the global system has been: we will give as much as we have to give but not more, and it will take a long time. For example, if you look at the way in which the reforms to the quota system in the IMF happened from 2010 onwards: it took forever to bring incremental changes to the voting proportions within the IMF. As China particularly has risen and has asserted itself, becoming the second largest economy, it has also felt much more confident about being able to cooperate in certain areas but to contest in others. You can call this contested cooperation. And you see that with several other developing regional powers or emerging powers from the global South. South Africa is an example of that. The country is not very powerful, but you find that it cooperates in certain institutions and helps to build them up, but in other cases, it complains about the fact that these institutions are not changing quickly enough. And then it works with China or Russia, who it believes are able to push for change or to create alternative global institutions in parallel, maybe not to replace but to contest the traditional ones.

Both of you have already hinted at repercussions on international cooperation and development cooperation. Do you dare to look a little bit into the future? What do you think will happen in this regard?

Imme Scholz: Let me start with a clarification of what I said before: the global order is also changing because it is being questioned by Western powers. The influence of Donald Trump cannot be underestimated, and I really thought I should reread the G-Zero book by Ian Bremmer ${ }^{36}$ - it is not US and China, it really seems to be Zero what we are seeing.

If we think of the impact of these changes on international cooperation, I see that sometimes the terms international cooperation and development cooperation are used interchangeably. The international cooperation system needs to be reformed and the $0.7 \%$ target ${ }^{37}$ which you mentioned in your introduction could really be a disincentive for modernising this system. In a way, it is part

37 Refers to the commitment stated by most DAC donors to achieve the target of spending 0.7 per cent of their GNI on ODA measures. For further information, see: https://www.oecd.org/dac/stats/the07odagnitarget-ahistory.htm (15.04.2020). 
of the old narratives, the outlived narratives that Elizabeth mentioned. Of course, I do not dismiss the claim of Least Developed Countries (LDCs). But questioning the $0.7 \%$ target is often, just for political reasons, interpreted as questioning the need for international cooperation for poverty reduction. But that is not the point.

What is becoming clear now is that the global system is changing very much and so many foundations we took for granted are shaking. International cooperation and development cooperation, you mentioned the altruistic justification, have always been part of the multilateral system of cooperation. So, if multilateralism is now being weakened - because more and more countries adopt a short-term perspective or see their national interests as juxtaposed to international cooperation because they understand it as a zero-sum game - then, international cooperation for preserving peace and the rule of law, and for working jointly towards what we define as shared interests or the global common good, will become more and more difficult. Elizabeth mentioned the keywords: it is mutual interests, it is commercial interests, and the need to reform multilateral institutions but it is not clear how to reach it. This means that we are in transition, but it is not clear where we are going exactly. Democratic countries interested in maintaining and reforming multilateralism need both a value-based and a pragmatic approach towards international cooperation at the same time. We cannot afford a purely value-based approach because we need to cooperate with countries with different value systems such as China and Russia. And we can no longer base this cooperation on the illusion that the richer China gets, the more liberal it will be and that by some miracle it will suddenly turn into a democracy. If you imagine democratic elections now in China, what would be the effect? Who and what types of programme would the Chinese electorate vote for? After decades without free public debate, without a free media, how would this large and heterogenous society achieve consensus on how to solve the challenges of the $21^{\text {st }}$ century? What role would they like to see their country play on the global arena? The need for renewed and energetic international cooperation is large and immediate which means that you have to look out for new partners and maintain old ones. It is new territory we are walking on. In that sense, depending on the objectives, we will have to look for a flexible geometry in international cooperation with variable alliances, and at the same time reform existing alliances. This is true as much for negotiations within the G20 as within the UN at large, within conventions (e.g. on climate) as well as within the $\mathrm{G} 7$, and at regional level.

Elizabeth Sidiropoulos: To pick up on the question of international versus development cooperation: in terms of development cooperation, I see it has become much more mercantilist, much more interest-driven. In terms of international cooperation, if we think about it in the bigger context of the global public 
goods, it is going to be a bit of a hybrid, and I suppose development cooperation will be as well. It is not that everybody has turned their back on recognising the importance of the SDGs or that there is not a need to cooperate to tackle today's challenges, whether we are talking about climate change or trade. I do not think that this is going to become what Ian Bremmer says in his book, 'every nation for itself', notwithstanding what is happening in the US. The problem is that the US acts almost as a lightning rod to which people or countries respond. When it takes on this highly nationalistic insular approach, other countries tend to respond accordingly, and that is critical. At the same time, at some levels there is international cooperation, there is political will. And I do not think that is going to be taken away.

But we need to let go of the belief that we are going to develop an entirely harmonised, universal approach to international cooperation, more importantly to measuring international cooperation or progress, etc. That is the bit about pragmatism that Imme was talking about. For me, the big challenge in the discussions around the SDGs is that we are coming in with different approaches to how to measure development and who is responsible. Imme used the example of the 0.7 per cent. If we are going in with certain red lines in this current milieu, we are not going to get results; we are not going to create opportunities to move beyond the deadlocks.

I fully agree. Let us look into the group of countries heading for ODA graduation. Do you think that the label of being eligible for ODA or being a highincome country affects the policy of their governments? How is ODA graduation affecting these countries internally?

Imme Scholz: Looking at the 2030 Agenda, the metrics for saying "international cooperation is needed to achieve those goals" is not the per capita income because it is a universal agenda which needs active participation by all countries. The metrics for graduating, 12,000 US dollars income per capita for three years in a row, are extremely simplistic. They are also part of the old narrative because we all know that a certain level of income per capita does not say anything about real income distribution, and it does not say much about the quality of public services. The need for cooperation and knowledge sharing and, to a certain extent, resource-sharing to solve urgent and major problems do not disappear when you reach this level of 12,000 US dollars income per capita for three years in a row. So, that is a mismatch in criteria.

In Europe today's variations of social security systems, workers' rights and collective rights and democratic institutions emerged in the $19^{\text {th }}$ and $20^{\text {th }}$ century. After two world wars the West found a way to achieve what Karl Polanyi ${ }^{38}$ 
described as the "great transformation" of capitalist economies into societies with social regulation and inclusive political institutions. Today, we know that this is not sufficient, and that the relationship between economies, societies and nature also needs to be transformed, as described in the flagship report of the WBGU in 2011. ${ }^{39}$ History usually does not repeat itself and developing countries are going through their own historical processes of conflict and learning. In the aid system, we did not find an answer yet to how to really promote or support the change in regulating systems to improve both the distribution of income and the provision of public services. A recent blog from the Centre for Global Development ${ }^{40}$ focuses on the impacts of graduation on the financing of public health services and universal health coverage. They looked at the experiences of several African countries with the Global Fund against AIDS, Tuberculosis and Malaria (GFATM) and specifically the dialogue instruments the Global Fund uses for reducing donor dependency and supporting partners in defining own priorities in health policy and practice. But its engagement in dialogue remained, as they called it, 'theatre' played with the donors - donordriven processes could not solve the fundamental problems of giving political priority to health issues and mobilise sufficient domestic financial resources which GFATM funding would have complemented in specific areas.

This is the difficulty we are facing. There were many efforts to solve the dependency problems aid creates, including the Accra Agenda on aid effectiveness, with weak results. At the same time, we see continuous need for investing in international cooperation for tackling common and global problems and have to become more effective jointly. The costs of failure will have a global dimension.

Elizabeth Sidiropoulos: I cannot speak for what the debate in many of these graduating countries may be, whether it is a debate happening at a very closed elite level, whether it matters or not. But you are looking at significant variations; countries in transition may have very different societies and public systems in place. Per capita income is an arbitrary figure and one that absolutely does not tackle the problem. In my own country, South Africa, we have the highest Gini coefficient in the world ${ }^{41}$. We are a middle-income country, but 20 minutes outside my office we have the poverty of any low-income country. The ODA categorisation by income per capita is a metric that maybe makes sense for economists, but it is increasingly being contested. Lorenzo Fioramonti from the University of Pretoria tackled many of these issues in a book called 'GDP'

39 WBGU 2011.

40 Sabino et al. 2020.

41 The Gini index measures the extent to which the distribution of income among individuals or households within an economy deviates from a perfectly equal distribution. 
in 2013. GDP referred to 'gross domestic problem' rather than the 'gross domestic product' ${ }^{42}$.

As regards the effect of graduation on actual policies, particularly if we look at countries in Africa, we are talking about states and governments that have begun, for example, to tackle some of the issues around domestic revenue generation in terms of taxation. But a lot of that is still, certainly if you are looking at lower-middle-income countries, coming from the commodity sector and from extractives. That link between a government's accountability to citizens as a result of taxation is still not there; that social contract is often missing. And that is part of addressing the issues around aid and dependency, which has not been overcome. Some of the discussions we have had here in southern Africa underline that you cannot take that metric at face value. But you also need to think about specific targeted engagements that are critical for development that ODA would have been able to help, even in countries that have reached a particular level of income. Health is one, issues around the justice system are another, or education and so on. And I am now looking at the South African case, which is often sui generis in the continent. Some of the development cooperation that is still coming in is highly targeted through government agencies to address these very significant structural problems. Graduation does not address the structural problems, whether they are economic or social. I think the criteria need to factor that in.

Allow me a very brief side question. If you look at the list of the 29, in a number of these countries people have called the entire set-up of their society into question in recent months. For instance, in Chile, a country that graduated in 2018, the people went onto the streets and said: we do not accept this system, we do not accept this government and we do not accept the way our society is structured any longer. I find this extremely interesting and I ask myself: should it give us hope that pressure changes things and that these countries will speed up on their route of development or is it a symbol of the danger that they are all caught in the middle-income trap?

Imme Scholz: The specific process of transformation and of changing the economy, the rules, the institutions and the capacities for having a more just society and a society which is more capable of change will be a specific story in each country. In Chile, of course, the story is very much linked to the dictatorship and how the transition from dictatorship to democracy was structured by the new constitution put in place under Pinochet. This constitution made it very difficult to revise the deregulation and privatisation decisions made in the 1970s and 1980s. That is what people are demonstrating against, and it is not clear 
what the result of the constitutional reform process will be. I was asked by Chilean friends what German cooperation can do to help Chileans to understand and actively shape the process of the new constitutional assembly they will have. I contacted several NGOs, and apparently the political party foundations have most liberty to act in this case. The large NGOs which receive funding from the official development budget cannot act because the country is no longer ODAeligible. In that sense, the graduation process means we are kicking the instruments we have for funding international cooperation out of our hands. I think it will come to the question of what the incentive can be for countries like Germany to continue investing in international cooperation, even if it does not factor into the $0.7 \%$ target.

But you were asking: Will we see positive changes in these countries? I think that we will see popular protests, but it is extremely unclear how they will be translated into political decisions and whether they will trigger a change for the better. The 2030 Agenda is innovative because it reminds us of the connections between altruism and realism. The 2030 Agenda is built on the conviction that in the $21^{\text {st }}$ century, most challenges that countries and societies are facing are of a global nature - either because they are caused by many and have an impact on all, or because they are common challenges shared by most. International cooperation helps to address both kinds of challenges, especially those which are of a systemic nature and too large for national problem-solving. Local failure will not only be felt locally. Therefore, it is both a matter of supporting fellow human societies and in our own social, economic and political interest to cooperate. With regards to Chile or other countries with social protest movements: If we are interested in keeping a peaceful order and in keeping the law of the jungle under control, we need to support the processes which help such protests have a productive outcome.

Elizabeth Sidiropoulos: Absolutely. There have been popular protests in many parts of the African continent as well in recent times. We saw some of them in the Arab Spring. South Africa, over the last six or seven years, experienced a mushrooming of popular protests, many of which are not even documented; some were only at local government level. The challenge that we have seen on the continent is to take the mobilisation of people on the streets into the corridors of power. There needs to be leadership and there needs to be a path to convert the popular protest into something tangible. You are not going to have anything concrete in the short term. Particularly where you have a military, a deep state - Egypt and probably Zimbabwe are interesting examples in that regard - you have people pushing for this change, but actually there is no change. Instead, it is simply the elite wearing a different outfit and re-entrenching itself. We also see that to some extent in South Africa. I do not think we have a deep state yet; we have state capture, but I think there is a recognition 
among some in the political elite of the need for change. But that change is coming very slowly. And it is going to be very different in different countries, given their different historical contexts.

In terms of the rationale for international cooperation, it is absolutely about the law of the jungle not being allowed to take over. And what does that mean? We have also been thinking about this in the conversations around a project on what South Africa's international relations should look like in the 2020s. And, maybe with the exception of the US and China, I think the rest of the world really does benefit from a system where the rule of law exists. It may not always be applied, we know that, but at least there are rules - it is not about "might is right" but about rules and regulations and norms.

Imme Scholz: And accountability.

Elizabeth Sidiropoulos: Yes. Especially in the Europe-Africa context, there should be a convergence of interests in international cooperation from northern as well as emerging countries because we have common interests. We also have certain common values; they might not be entirely the same, but we recognise that, for instance, if we do not tackle climate change effectively, we are all going to suffer. Similarly, having rules regulating trade ensures you do not have a sort of gunboat diplomacy (when Major Perry arrived with his gunboats in Japan in the 1860s and said: "Open up your market.") We do not want that kind of thing. We should all be working together: like-minded countries who are small, who are middle powers, who are regional powers, because it is in our interest to ensure that the unilateral G-Zero, the 'everybody for himself' kind of world is not in our interest; not at a time when some of the biggest challenges we are facing are transnational.

Going forward, if we are having a conversation about international cooperation, that is also about how we are engaging and cooperating at a domestic level with the said graduating countries because they can be important drivers in their region, and also about how we can make sure that there is a balance between domestic and global cooperation, on issues like climate change, specifically.

We have been talking already about the value-based approach and briefly touched upon the role of a country like Germany. What role should it assume vis-à-vis the countries moving towards graduation? What should Germany change in its international approach and in its international cooperation?

Imme Scholz: From the perspective of a universal agenda for change, the cooperation system should transit towards a goal-based system and not a countrygrouping-based system. At the same time, we know that geographic location makes a big difference, and everybody agrees that it is Europe which should invest especially in cooperation with Africa and with the Mediterranean and 
Near or Middle East. On the other hand, the ties Germany has with China are completely independent from it being on a graduation list or not. In that sense, Germany as a country needs a nuanced approach, both geographically, what we call the neighbourhood and the broader neighbourhood around the EU, and with respect to policy areas. It should also look at what the importance of German engagement is in comparison with other powers. What is the EU doing, what is Germany doing and what are other strong actors doing? In that sense, it is great that we have the 2030 Agenda and the SDGs because they are relevant domestically and internationally across ministries, and we have seen that very clearly in Germany. The Agenda is not embraced only or most strongly by the Ministry for Economic Cooperation and Development, BMZ. We have the Ministry of the Environment, we have the Ministry of Health, but then we do not see concomitant increases in funding for international cooperation across these ministries. That is clearly lagging behind. But it will be a mixture of policy-areaoriented goals like climate and also geographical targeting.

In that sense, you have to think of the broader picture, beyond how it always was - Europe and Africa, or North America and South America. For Latin Americans, their relationship with Europe has always been important as a counterweight to North America. But the signs are not looking so good for the broader picture because our capacities are absorbed between China, the US, the Middle East and Africa. From the perspective of maintaining and defending the multilateral cooperation system, that is not satisfactory.

I think that Germany needs to step up its capacities for international cooperation, knowledge-wise but also policy-wise. We have underdeveloped capacities for that across the board and in the ministries. They have sector capacities but not country capacities and, typically for a large economy, we look inwardly too much and not sufficiently outwards.

Elizabeth, you are from South Africa. What do you recommend Germany to do regarding our international policy on countries moving up the income ladder and eventually approaching graduation?

Elizabeth Sidiropoulos: First, it is important to note that Germany, probably unlike many other European countries, is viewed fairly positively on the African continent. That is important in terms of cooperation. Notwithstanding Namibia perhaps, Germany is viewed differently from, for example, France, and that is important to recognise - also in the context of two key issues that dominate the discussion between Africa and Europe: migration and violent extremism. The two are interrelated and have an impact on how European and bilateral cooperation plays itself out in Africa, particularly around development support. A lot of the assistance is being securitised and linked to migration. A lot of the support to countries in East Africa, in North Africa and to the Sahel is based on that linkage. And that also addresses the issue of what values Europe and 
Germany are advancing, and it is not necessarily seen through the prism of human rights or good governance or democracy. Moreover, just to mention it briefly, talking about international cooperation, Europe as a whole needs to think about the fact that European taxation systems actually enable some of the theft and growing inequality in certain countries.

I think there are a number of areas where Germany is really well positioned to take advantage of the upcoming graduation of countries, in terms of cooperation. Technology cooperation, science and innovation cooperation play an important role and could be linked again to climate, to specific SDGs. This kind of cooperation, both at a research level and at a technical level in agencies, could be extremely useful, and could also help to create sectoral opportunities in those countries for investment, because, ultimately, that is also key for many of these countries. Some of them might be graduating, but they need to also build up their economic sectors in terms of services and manufacturing at the same time. This requires a highly nuanced approach.

I think the point is about looking at this through a different lens: it is not just about whether a particular country has reached a particular level in terms of income, but about which of the big challenges, as reflected in the SDGs, are acutely felt in particular countries and regions - some of the issues around energy, water, climate change and resources on land. It makes sense to look at the broader ramifications for the region and develop international cooperation that takes those issues into account. It is important to look at these challenges regionally because that also includes graduating countries which can act as motors, and you can probably get 'more bang for your buck' than if you think about it only in one particular country.

We have already discussed that multilateralism is not in a very good state right now and my question is: Will the changes in the international system and a number of countries moving towards ODA graduation be helpful or detrimental to the multilateral system? You mentioned that emerging countries want to leave their individual imprint and may become less willing to be bound by existing international law. Do we have to fear that a higher number of countries reaching high-income status might mean a death blow to multilateralism?

Imme Scholz: Well, if we take Turkey, we are talking about Erdogan Turkey and if we are talking about Brazil, we are talking about Bolsonaro Brazil. But two years ago, it was not Bolsonaro Brazil. That is why I said we need to step up our knowledge capacities. We need to understand those countries much better. I do not think it is automatic that countries move to a higher income status and then suddenly become unilateralists or apply 'my country first' approaches. Even Bolsonaro has seen that Trump does not do many things in his favour. 
So, I think in a way we are confronted with our own legacy, because we in the West thought that we could just pretend that the multilateral and rule-based system would go on as it was although it did not work well for all countries across the globe. We did not have war between rich countries, but we had a lot of wars in developing countries, and it is this kind of blindness and double standards which are now falling back down onto us. And they are falling onto the multilateral system. It will not help us to defend multilateralism if we deny that part, the dark side of the history, of the last few decades, and how development cooperation was also a part of that. That is what I like about Macron's approach. I think it was in 2018 when he claimed in a speech before the UN general assembly: We need to change the multilateral system. ${ }^{43}$ And changing it also means accepting that our role in it and our weight will be diminished. As Elizabeth said, there are two large countries which can try to impose their will, but the rest of us are small.

Elizabeth Sidiropoulos: I think the first point is that multilateralism is a very important principle that all African countries subscribe to. Having said that, I believe it is also important for Europe and others to recognise that the current institutions of multilateralism must change. If I just look at my country, South Africa is a committed multilateralist. But it does not always agree with the way in which things have been run, or who calls the shots, or the informal rules of multilateralism, and believes these need to change. There is a big challenge for Europe and for the US worth discussing today. At some point, some of the countries that are committed multilateralists will just give up trying to reform the present system, if the present system does not change markedly and quickly enough. If it takes you eight years to agree on whether you are going to give up five percentage points of voting rights in the IMF or whatever it is, that is a problem. Because at some point someone will say: to hell with you, I am going to set up my own structures. Of course, South Africa cannot do that on its own, Egypt cannot do it on its own and Brazil cannot do it on its own, but they can hitch their wagon, as I said, to other countries that are perhaps less committed multilateralists. The first big challenge and the urgency is for key countries that have power in the multilateral institutions, and it is not just the US, to really drive a reform agenda together with developing countries, with key developing countries. It is about relinquishing power, and perhaps the best example happened in my country with Frederik Willem de Klerk in 1990. Nobody thought on 2 February 1990 that he would start a process whereby the National Party would actually relinquish power. But it happened and it happened peacefully. If the West keeps on holding onto power and giving as little as it possibly can, the polarisation within the multilateral system is going to grow. 
On the role of graduating countries: in many ways, their development can enrich the multilateral system, but it will also make it much more difficult. If you are looking at countries that are now moving up the income chain, these countries are also developing more agency. And if you develop more agency, you will also feel more empowered to come in with your own positions and articulate them, whereas in the past you may have had a position, but you were a little unsure of yourself and did not want to play that role. That means that it is going to become messier, if it was not already messy enough, in terms of global negotiations or any agreement on metrics or how you evaluate this or how you move forward on that. But that does not necessarily have to be bad for multilateralism, provided we are all moving in the same direction. Some of my colleagues and South Africans have been very keen on the arrival of the multipolar world. But the arrival of the multipolar world does not necessarily mean that it is going to be easily more multilateral.

As a last question, or closing statement, what aspect do you think has been missing? What would you like to add about ODA graduation in times of changing global relations and partnerships?

Imme Scholz: Maybe we should look into the incentives or how to motivate other ministries to invest more in international cooperation and, at the same time, learn from what did work in the aid world and what not. Let me give another example: I am part of the Global Health Hub Germany ${ }^{44}$, a multi-stakeholder platform created around the German Ministry of Health's approach to embracing a global health policy and for enabling all types of actors to cooperate in global health. This is a very laudable initiative and badly needed in a globalized world where health systems are weak in many countries with large or growing populations. The platform was welcomed by many scientists, NGOs and health professionals. It is, however, unclear how the voluntary engagement of these stakeholders in identifying new areas of cooperation in global health will be linked to the health ministry's own activities in this area or whether there will be additional funding for non-state activities. If things are kept separate that way, the Hub will work below its potential. There is clearly room for more engagement and innovation to strengthen multilateral international cooperation under new framework conditions.

Elizabeth Sidiropoulos: To look at that from the opposite point of view, it is also important from the side of graduating countries to engage and develop

44 The Global Health Hub Germany is a platform funded by the Federal Ministry of Health. It aims to connect people and organisations who are "committed for a [sic] better health for all people all over the world" and enable them to work together for interactive and interdisciplinary solutions. For more information, see https://www.globalhealthhub.de/en (15.04.2020). 
domestic constructions and frameworks for international cooperation. Some emerging donors and powers are establishing their own agencies and systems to carry out international cooperation. And this could also be about exploring the opportunities of how international actors like GIZ might engage to encourage that, also in graduating countries, and about linking it back to some of their national development objectives as well as the SDGs.

In the end, this is a changing world and we have been discussing here about a framework that has been in existence from before this time, from before the huge seismic shifts of the last four to five years. We need a bit of a paradigm shift in that as well. This discussion, I think, is part of that. But we really need to be moving some of the big international institutions into a new sphere of thinking about ODA.

Imme Scholz: I have been thinking about the processes which Polanyi describes in "The Great Transformation". He paints a very stark picture of how long the wealthy and the powerful could not see how they could spare a pound or a mark for the redistribution of incomes and social systems. They could not see it. And I think this is exactly our blindness now. We cannot see how important it is to invest in this international cooperation. We prefer to go on with our spending routines within Germany, and we do not see the need to invest more and differently in international cooperation. That is the blindness we have now. 
